\title{
Uso de resíduo da produção de alumina eletrofundida na produção de blocos e telhas cerâmicos
}

\section{(Use of electro-fused alumina production waste for the production of ceramic bricks and roof tiles)}

\author{
R. R. Menezes ${ }^{1}$, L. N. Marques $^{2}$, L. N. L. Santana ${ }^{2}$, R. H. G. A. Kiminami ${ }^{3}$, G. A. Neves ${ }^{2}$, H. S. Ferreira ${ }^{2}$ \\ ${ }^{1}$ Departamento de Engenharia de Materiais, Universidade Federal da Paraíba, Cidade Universitária \\ João Pessoa, PB 58059-900 \\ ${ }^{2}$ Departamento de Engenharia de Materiais, Universidade Federal de Campina Grande, Campina Grande, PB \\ ${ }^{3}$ Departamento de Engenharia de Materiais, Universidade Federal de S. Carlos, S. Carlos, SP \\ romualdomenezes@ct.ufpb.br,gelmires@dema.ufcg.edu.br
}

\begin{abstract}
Resumo
A indústria de produção de alumina eletrofundida gera atualmente um resíduo durante o seu processamento, entretanto, a inclusão do resíduo em um ciclo produtivo representa uma alternativa de reciclagem importante tanto econômica como ambientalmente. Assim, esse trabalho tem por objetivo a caracterização do resíduo da produção de alumina eletrofundida e a avaliação de sua aplicabilidade como matéria-prima cerâmica alternativa para a produção de blocos e telhas cerâmicos. O resíduo foi caracterizado através da determinação de sua composição química e mineralógica, por difração de raios X e determinação de sua distribuição de tamanho de partículas. Foram formuladas composições de massa cerâmica incorporadas com o resíduo e confeccionados corpos-de-prova por prensagem uniaxial. Os corpos-de-prova foram queimados e em seguida foram determinados a absorção de água, a retração de queima e o módulo de ruptura à flexão. Pode-se concluir que o resíduo apresenta elevada finura e constituído basicamente por alumina e pequenos teores de metais e óxidos fundentes e que é possível a incorporação de até $20 \%$ de resíduo em formulações para a produção de blocos e telhas cerâmicos

Palavras-chave: resíduo, reciclagem, blocos cerâmicos, telhas.
\end{abstract}

Abstract

The industry of electro-fused alumina production actually generates a waste during its processing, however, the inclusion of wastes into productive cycles represents an alternative form of restoration, which is interesting from both environmental and economic standpoints. This work has as aim the characterization of the electro-fused alumina production waste and the evaluation of its suitability a alternative ceramic raw material for the production of bricks and roof tiles. The waste was characterized by chemical composition determination, X-ray diffraction and particle size distribution determination. Several formulations were prepared and samples bodies were prepared by uniaxial pressing. The sample bodies were fired at different temperatures. Sintered samples were characterized in terms of water absorption, firing linear shrinkage and mechanical strength. The results showed that the waste is basically composed by alumina and small amounts of metals and fluxing oxides and that is possible incorporations of up to $20 \%$ in formulations for the production of ceramics bricks and roof tiles.

Keywords: waste, recycling, ceramic bricks, roof tiles.

\section{INTRODUÇ̃̃OO}

O aproveitamento dos rejeitos através de estudos capazes de detectar suas potencialidades e viabilizar sua seleção preliminar é encarado hoje como atividade complementar, que pode contribuir para diversificação dos produtos, diminuição dos custos finais, além de resultar em "novas" matérias-primas para uma série de setores industriais.

A deposição de resíduos industriais em aterros, além dos elevados custos econômicos, pode trazer inúmeros problemas ambientais, como contaminação do solo, do lençol freático e agressão a vegetação presente no local. Nesse sentido a re-utilização e a reciclagem são as soluções mais indicadas para o manejo da grande maioria dos resíduos industriais, reduzindo custos, preservando recursos naturais não renováveis, diminuindo a carga de poluentes lançados no meio ambiente [1-3]. A reciclagem teve seu início juntamente com a revolução industrial, que trouxe consigo a geração de grande quantidade de resíduos e o aumento de materiais e produtos descartados com a intensificação das relações de consumo, mas ganhou grande evidência nas últimas décadas com o intenso crescimento na geração de resíduos sólidos, 
com destaque para os industriais. Nos últimos anos, a pesquisa sobre a reciclagem de resíduos industriais vem se intensificando em todo o mundo, no entanto, ainda possui índices insignificantes frente os milhões de toneladas de resíduos inorgânicos que são produzidos a cada dia $[4,5]$. O que evidencia que a busca de alternativas de reciclagem que conciliem as necessidades ambientais e o fator econômico é uma questão de suma importância para se ter crescimento econômico aliado ao desenvolvimento sustentável. A inserção dos resíduos num ciclo produtivo representa uma opção de recuperação alternativa desses materiais, que é interessante tanto no aspecto ambiental, como no econômico. Nesse sentido, a indústria cerâmica vem demonstrando grande potencial para a reutilização de resíduos inorgânicos [6]. Cerâmicas tradicionais, como telhas, blocos e revestimentos cerâmicos, geralmente, apresentam grande variação composicional, devido ao largo intervalo de composições das argilas utilizadas como matérias-primas para sua fabricação, o que possibilita uma grande tolerância para a incorporação de grandes quantidades de resíduos inorgânicos. O potencial de incorporação de resíduos nas formulações de cerâmicas tradicionais, aliado as elevadas quantidades de recursos naturais consumidos a cada dia por esse segmento industrial, ressalta a importância da reutilização de resíduos como matérias-primas cerâmicas alternativas, racionalizando o uso dos recursos naturais [7-9]. A diminuição gradual na abundância dos recursos minerais causou a recente tendência em substituir minerais por fontes alternativas de matériasprimas, que estão disponíveis em abundância, como os resíduos industriais e de mineração [9-14].

A indústria de produção de alumina eletrofundida gera atualmente um resíduo durante o seu processamento, que consiste em um pó, de granulometria fina, rico em óxido de alumínio, cujo manuseio provoca a formação de névoa e poeiras dificultando sua reutilização no processo produtivo, por ser arrastado facilmente pelas correntes de gases e possuir um rendimento extremamente baixo quando de sua re-inserção no processo. Em conseqüência disso, esse produto, é descartado pelas empresas em aterros particulares, todavia em virtude do volume gerado passará a ser descartado em aterros industriais, seguindo as normas técnicas. O resíduo gerado provoca uma série de implicações econômicas, associadas a sua adequada manipulação, descarte e monitoramento no aterro, o que vem se tornando uma fonte de custos para o setor. Assim, esse trabalho tem por objetivo a caracterização do resíduo do pó de coletor da produção de alumina eletrofundida e a avaliação de sua aplicabilidade como matéria-prima cerâmica alternativa para a produção de blocos e telhas cerâmicos.

\section{MATERIAIS E MÉTODOS}

Foram utilizados os seguintes materiais: resíduo proveniente do pó de coletor da produção de alumina eletrofundida, e argila vermelha proveniente da Cerâmica Espírito Santo, já utilizada na produção de blocos e telhas. A argila vermelha foi estudada anteriormente [15] e é constituída por caulinita, quartzo e mica, apresenta uma larga distribuição de tamanho de partículas $\left(\mathrm{D}_{10}=2 \mu \mathrm{m}\right.$ e $\left.\mathrm{D}_{90}=60 \mu \mathrm{m}\right)$, com tamanho médio de partículas de 8,22 $\mu \mathrm{m}$.

O resíduo foi caracterizado por meio de: determinação da sua composição química por fluorescência de raios $\mathrm{X}$ (Shimadzu EDX-720), ensaio semi-quantitativo usando amostra prensada e seca (sem utilização de ligantes) e tubo de raios $\mathrm{X}$ de $\mathrm{Rh}$; difração de raios X (Siemens D5005) com radiação $\mathrm{Cu}-\mathrm{k} \alpha$ com varredura de $2 \theta$ de 5 a $70^{\circ}$ e condições de operação de $40 \mathrm{kV}$ e $30 \mathrm{~mA}$ (com tempo de aquisição de sinal de $0,6 \mathrm{~s}$ por passo); determinação da distribuição do tamanho de partículas (Cilas, 1064LD) utilizando o princípio da difração de laser e sendo a amostra preparada segundo a metodologia normatizada [16] para análise granulométrica de solos (usando agitador de alta rotação e hexametafosfato de sódio como agente dispersante). Para os ensaios de caracterização o resíduo foi cominuído em almofariz e passado em peneira com abertura de 0,074 mm (ABNT 200), à exceção do ensaio de determinação da distribuição granulométrica, para o qual os resíduos foram apenas passados em peneira com abertura de $0,180 \mathrm{~mm}$ (ABNT 80) para desaglomeração. Os resíduos foram secos a $100{ }^{\circ} \mathrm{C}$, desaglomerados em moinho de bolas e peneirados através de peneira com abertura $0,180 \mathrm{~mm}$ (ABNT 80). Em seguida foram preparadas formulações através da mistura a seco em moinho de bolas por $2 \mathrm{~h}$ do resíduo e da argila vermelha. As proporções de resíduo adicionado a argila vermelha foram de 5, 10, 15, 20, 25 e $30 \%$. Após mistura em moinho de bolas, as formulações foram novamente passadas por peneira com abertura 0,180 mm (ABNT 80). Em seguida foram confeccionados corpos de prova de $60 \mathrm{~mm}$ x $20 \mathrm{~mm}$ x $5 \mathrm{~mm}$ por prensagem uniaxial a $27 \mathrm{MPa}$ que foram queimados a 900, $950 \mathrm{e}$ $1000{ }^{\circ} \mathrm{C}$ a uma taxa de $3{ }^{\circ} \mathrm{C} / \mathrm{min}$. Após queima, os corposde-prova foram submetidos a ensaio de caracterização física, com determinação da retração linear de queima, absorção de água (através do ensaio de imersão por 24 h) e módulo de ruptura a flexão em três pontos (com velocidade de aplicação de carga de $0,5 \mathrm{~mm} / \mathrm{min}$ ).

\section{RESULTADOS E DISCUSSÃO}

A Fig. 1 apresenta a curva de distribuição de tamanho de partículas do resíduo estudado. O resíduo apresenta uma distribuição de tamanho de partículas que para cerâmica vermelha pode ser considerada estreita, com $\mathrm{D}_{10}$ de $0,9 \mu \mathrm{m}$ e $\mathrm{D}_{90}$ de $19,9 \mu \mathrm{m}$ e tamanho médio de partícula de $9,5 \mu \mathrm{m}$. $100 \%$ do material apresenta tamanho de partícula inferior a $50 \mu \mathrm{m}$, com concentração de partículas em torno de 10 a $20 \mu \mathrm{m}$.

Uma massa cerâmica não é constituída apenas por argilas (em virtude de dificuldade que surgem no processamento), é formulada contendo materiais plásticos e não plásticos, o que acarreta uma "mistura" de granulometrias, sendo a fração mais "fina" associada à argila e as demais ("mais grosseira") relacionadas aos materiais friáveis. O resíduo atuará como material não plástico na massa. No entanto, para 
que materiais não plásticos possam agir com eficácia sobre as características das argilas, devem possuir granulometria acima de $60 \mu \mathrm{m}$ e ser usados em quantidades moderadas [17]. A adição de não-plásticos provoca a formação de pontos de descontinuidade entre as partículas argilosas, o que produz poros, que, em determinada quantidade permiti a passagem da água do interior da peça para a superfície, reduzindo tensões do processo de secagem sem comprometer a qualidade da peça. Ademais, os não-plásticos possibilitam ainda a diminuição da retração de secagem e queima. O uso inadequado dos não plásticos, por outro lado, pode diminuir acentuadamente a inter-conectividade da matriz vítrea e aumentar excessivamente a porosidade, comprometendo o desempenho da peça.

Como observado na Fig. 1, o teor de finos é muito elevado no resíduo, o que pode comprometer sua ação como não plastificante na massa, aumentando a porosidade do sistema e comprometendo seu desempenho. Nesse sentido, pode-se utilizar o diagrama de Winkler [17] a fim de avaliar se a granulometria do sistema analisado está dentro da região do diagrama que é indicado para a produção de blocos e telhas. As massas analisadas encontram-se no limite inferior do diagrama, em virtude da elevada fração de material abaixo de $2 \mu \mathrm{m}$ e entre 2 e $20 \mu \mathrm{m}$, o que pode implicar em dificuldades de processamento e comprometimento das características físicas da peça após queima. No entanto, vale salientar que trabalhos [18-20] analisando a viabilidade de utilização de argilas em cerâmica vermelha observaram que argilas que não se encaixavam na região correspondente do diagrama de Winkler eram adequadas a produção de blocos cerâmicos.

A Tabela I apresenta a composição química semiquantitativa do resíduo estudado. O resíduo é constituído basicamente por $\mathrm{Al}_{2} \mathrm{O}_{3}$ e $\mathrm{SiO}_{2}$, com menores teores de $\mathrm{K}_{2} \mathrm{O}$ e $\mathrm{Fe}_{2} \mathrm{O}_{3}$. A presença do $\mathrm{SiO}_{2}, \mathrm{~K}_{2} \mathrm{O}$ e $\mathrm{Fe}_{2} \mathrm{O}_{3}$ está associada as impurezas presentes nas matérias-primas para produção da alumina eletrofundida. Observa-se também a presença de vários metais pesados e de enxofre no material. A presença de óxidos fundentes pode favorecer a atuação do resíduo como um fundente no processo de queima, no entanto, frente o elevado teor de alumina essa ação pode ser minimizada nas temperaturas de queima da cerâmica vermelha, passando o resíduo a atuar apenas como uma matéria-prima não plástica de enchimento. Não se observou teores de $\mathrm{Na}_{2} \mathrm{O}$ no resíduo, apesar de vários ensaios de fluorescência em várias frações do material analisado, o que não pode ser explicado até o momento, já que se esperavam teores de sódio no material por esse ser um contaminante presente na matéria-prima do processo. Observam-se pequenos teores de enxofre no

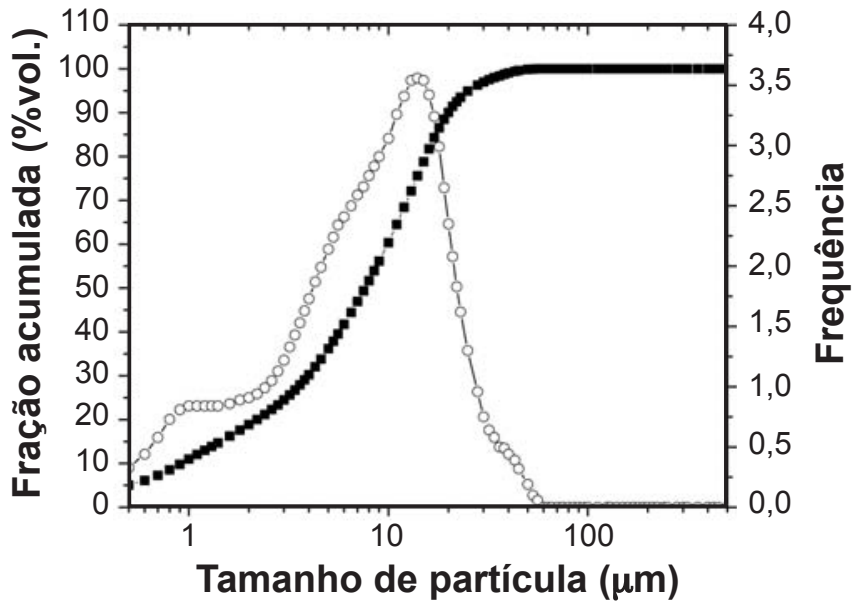

Figura 1: Distribuição de tamanho de partícula do resíduo estudado. [Figure 1: Particle size distribution of the studied waste.]

material, que associados aos resíduos de carbono presentes no material analisado (o equipamento de EDX utilizado não possui capacidade de deteç̧ão do carbono), indicado pela perda ao fogo e pela presença visual no próprio material, podem atuar, gerando gases durante a queima o que pode dificultar a utilização de elevadas quantidade de resíduo na massa. A geração de gases durante o processo de queima pode aumentar a porosidade do sistema, bem como, favorecer o desenvolvimento de microtrincas e defeitos, diminuindo a resistência do sistema.

A Fig. 2 apresenta o difratograma de raios $\mathrm{X}$ do resíduo estudado. $\mathrm{O}$ resíduo apresenta como fases cristalinas o coríndom (alumina $\alpha$ ), alumina $\gamma$ (em pequena quantidade), outra fase polimórfica da alumina, um sulfeto de potássio, alumínio e uma liga ferro-titânio. Constata-se que o resíduo apresenta uma larga variedade de constituintes, com alguns deles podendo comprometer o processo de densificação dos blocos e telhas durante a queima. Os metais, apesar de estarem em pequenas quantidades, podem alterar a densificação do corpo em virtude de sofrerem processos de expansão (associados a sua oxidação) concomitantemente a retração do corpo cerâmico durante o processo de queima. $\mathrm{O}$ sulfeto de potássio ira se decompor durante a queima liberando gases, o que também podendo alterar a cinética de densificação do corpo.

As Figs. 3, 4 e 5 apresentam as retrações lineares de queima, as absorções de água, e os módulos de ruptura à flexão dos corpos-de-prova com incorporações de resíduo, respectivamente. Com base na Fig. 3 observa-se que a incorporação do resíduo não provocou alterações

Tabela I - Composição química do resíduo estudado (\% massa).

[Table I-Chemical composition of the studied waste (wt.\%).]

\begin{tabular}{lcccccccccc}
\hline & $\mathrm{Al}_{2} \mathrm{O}_{3}$ & $\mathrm{SiO}_{2}$ & $\mathrm{~K}_{2} \mathrm{O}$ & $\mathrm{Fe}_{2} \mathrm{O}_{3}$ & $\mathrm{SO}_{3}{ }^{\mathrm{a}}$ & $\mathrm{MgO}$ & $\mathrm{MnO}$ & $\mathrm{TiO}_{2}$ & $\mathrm{ZnO}$ & $\mathrm{PbO}$ \\
\hline Resíduo & 71,19 & 9,85 & 5,11 & 2,59 & 2,25 & 0,75 & 0,53 & 0,49 & 0,41 & 0,31 \\
\hline
\end{tabular}

${ }^{a}$ A perda ao fogo total foi $4,81 \%$. 


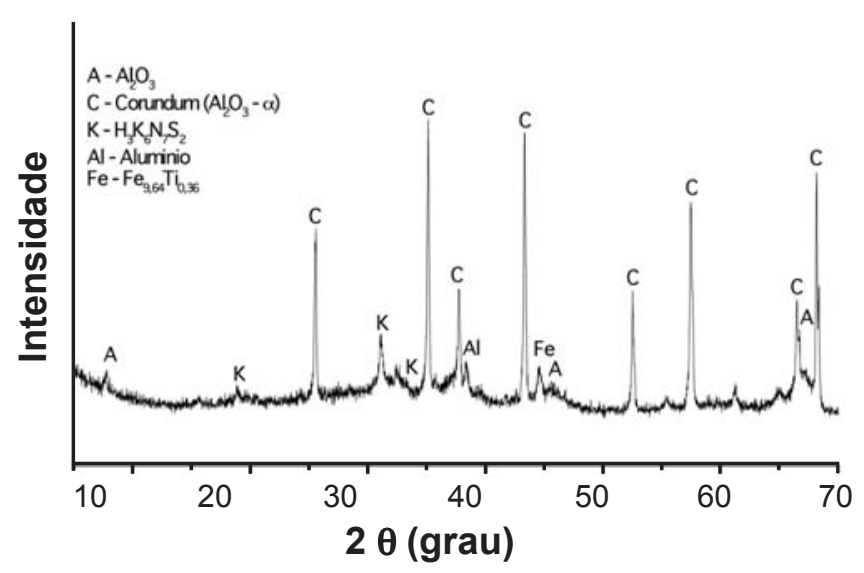

Figura 2: Padrão de difração de raios $\mathrm{X}$ do resíduo estudado.

[Figure 2: X-ray diffraction patterns of the studied waste.]

significativas na retração de queima nas temperaturas de queima de 900 e $950{ }^{\circ} \mathrm{C}$, sendo observado apenas uma leve diminuição da retração quando da adição de elevados teores de resíduo, 25 a 30\%. No entanto, quando da queima a $1000{ }^{\circ} \mathrm{C}$, o resíduo teve marcante influência na retração dos corpos-de-prova, sendo observada, de forma geral, uma diminuição na retração do material com o aumento no teor de resíduo. Este fato está associado à diminuição na quantidade total de material argiloso nos corpos e a presença de um material não plástico, cuja principal função seria de "enchimento" nas temperaturas de queima praticadas. Por outro lado, é interessante que quando da adição de $5 \%$ de resíduo e queima a $1000{ }^{\circ} \mathrm{C}$, a retração do sistema foi levemente superior (considerando o desvio padrão) ao da argila pura, o que pode está associado ao teor de fundentes do resíduo que pode ter contribuído para o aumento da quantidade de fase líquida e favorecido a retração do sistema.

Na Fig. 4 verifica-se que a absorção de água dos corpos contendo resíduo, de forma geral, aumentou com o teor de

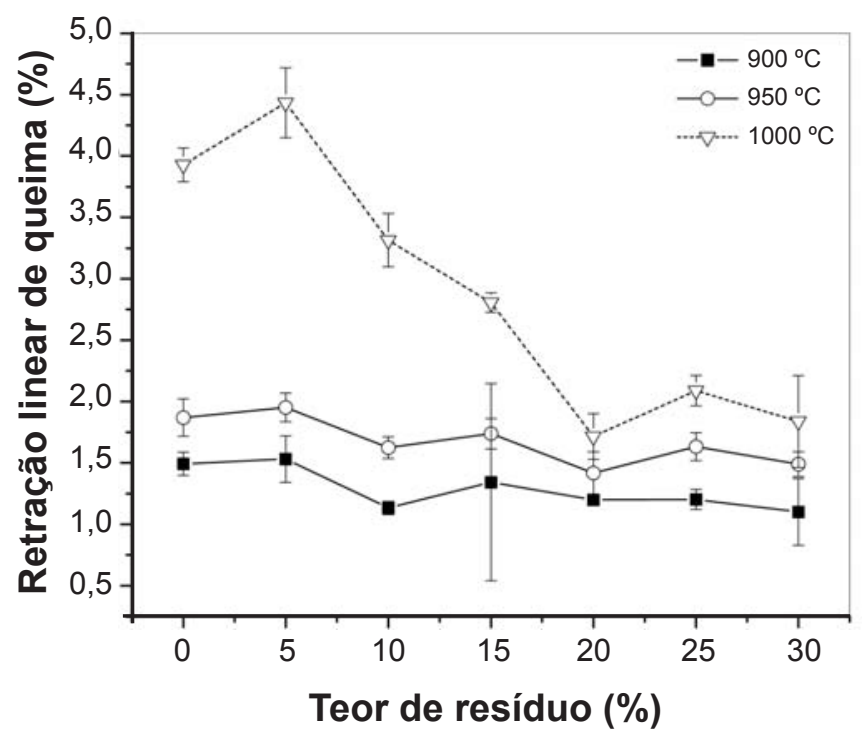

Figura 3: Retração linear de queima das formulações estudadas. [Figure 3: Linear firing shrinkage of the studied formulations.]

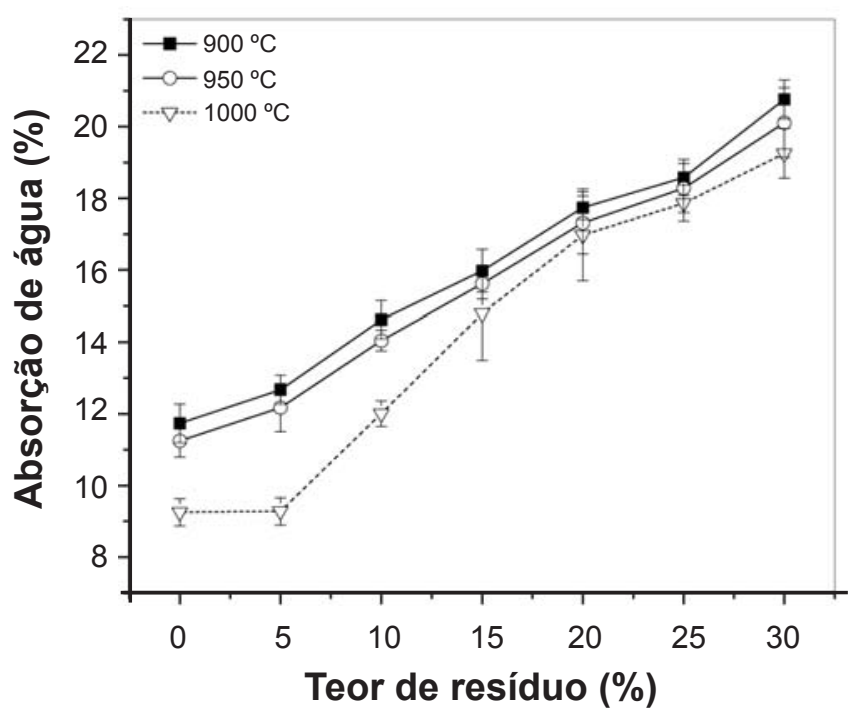

Figura 4: Absorção de água das formulações estudadas.

[Figure 4: Water absorption of the studied formulations.]

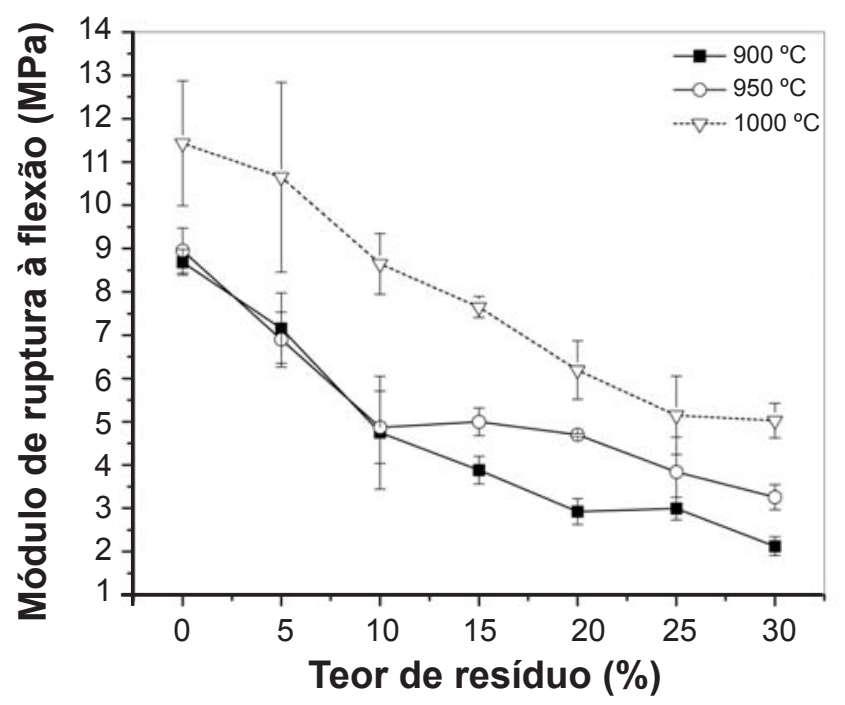

Figure 5: Módulo de ruptura das formulações estudadas. [Figure 5: Modulus of rupture of the studied formulations.]

resíduo, independentemente da temperatura de queima. Apresentando aumentos expressivos quando da adição de elevadas quantidade de resíduos, superiores a $15 \%$. A adição de $5 \%$ de resíduo quando da queima a $1000{ }^{\circ} \mathrm{C}$ não provocou alterações na absorção do material, o que vem ao encontro dos dados de retração que evidenciam que a adição de $5 \%$ nessa temperatura não diminui a retração de queima. Nesse sentido é interessante que os corpos queimados a 900 e $950^{\circ} \mathrm{C}$ apresentaram um aumento acentuado da absorção mas não uma diminuição na retração, tal como era de se esperar, diminuição da retração, há mais poros no material após queima e, por conseguinte, há uma maior a absorção.

Esse comportamento aparentemente destoante quando da queima a 900 e $950{ }^{\circ} \mathrm{C}$ pode está associado ao empacotamento do sistema argila-resíduo. Considerando a densidade real da argila [16] e a densidade real do resíduo, 
pode-se calcular a densidade relativa dos corpos-de-prova após prensagem e secagem a $110{ }^{\circ} \mathrm{C}$. A densidade relativa dos corpos contendo apenas argila foi de $63 \%$, um valor alto, que indica que a massa utilizada apresenta um bom empacotamento dos seus constituintes. Quando da adição de $5 \%$ de resíduo a densidade relativa caiu para $60 \%$, atingindo 59 e $48 \%$ nos corpos contendo 10 e $30 \%$ de resíduo, respectivamente. Assim, observa-se que a adição do resíduo, apesar de sua elevada finura, comprometeu o empacotamento do sistema. Então, mesmo não alterando significativamente a retração do sistema, como no caso das temperaturas de queima de 900 e $950{ }^{\circ} \mathrm{C}$, o resíduo propicia a obtenção de maiores absorções de água, tal como observado na Fig. 4, já que nessas temperaturas de queima, aparentemente, ele atua apenas como material inerte, sem função auxiliar de fundente. Por outro lado, quando da queima a $1000{ }^{\circ} \mathrm{C}$, aparentemente há o desenvolvimento de maior fase líquida (aumento significativo na retração do sistema sem resíduo), e com uma quantidade muito grande de fase líquida é possível o re-arranjo das pequenas partículas do resíduo em virtude da tensão capilar, quando da sua presença em pequenos teores (incorporação de 5\%). Entretanto, quando se tem muito resíduo há uma interação entre as partículas dos materiais não plásticos diminuindo a possibilidade de retração do sistema, o que pode ser visto ao se analisar a retração dos corpos contendo teores acima de $10 \%$ de resíduo e queimados a $1000{ }^{\circ} \mathrm{C}$.

A Fig. 5 ilustra que a resistência mecânica, de forma geral, decresceu significativamente com o aumento do teor de resíduo incorporado em todas as temperaturas de queimas. O que vem ao encontro do observado na Fig. 4 com o aumento da absorção de água nos corpos incorporados com resíduo. A composição com 5\% de resíduo não apresentou alteração no módulo de ruptura quando da queima a $1000{ }^{\circ} \mathrm{C}$ (considerando o desvio padrão calculado), o que esta de acordo com o observado nas Figs. 3 e 4 . Assim, verifica-se que é possível a incorporação de pequenas quantidades de resíduo sem alteração nas características mecânicas do sistema.

Com base em indicações da literatura [21, 22], as formulações contendo teores de até $20 \%$ de resíduo podem ser utilizadas em cerâmicas vermelhas, por apresentarem valores de absorção de água e módulo de ruptura dentro dos limites preconizados para os corpos-de-prova de cerâmica vermelha. Após queima a 900 e $950{ }^{\circ} \mathrm{C}$, a formulação com incorporação de $5 \%$ de resíduo pode ser utilizada para a produção de blocos furados e telhas [21]. Com a queima a $1000{ }^{\circ} \mathrm{C}$ as formulações com adições de até $20 \%$ de resíduo podem ser utilizadas para a produção de blocos furados e telhas.

$\mathrm{Na}$ grande maioria dos trabalhos [8, 10, 11, 23-25] envolvendo reciclagem de resíduos industriais e minerais através de incorporação em formulações cerâmicas para a produção de blocos e telhas, ficou evidenciada a possibilidade de incorporação de grandes quantidades de resíduo nas formulações sem deterioração significativa das propriedades das peças produzidas. No entanto, esses trabalhos utilizaram resíduos mais grosseiros e reativos (nas temperaturas utilizadas) que o resíduo do pó de coletor, que apresenta uma finura não encontrada na grande maioria dos resíduos industriais. Assim, evidencia-se que a capacidade de absorção de resíduo pelas massas cerâmicas não está apenas associada a sua composição química, mas também a sua granulometria, sendo necessário que o resíduo que vá atuar como material não plástico (e inerte) tenha granulometria semelhante as das matérias-primas não plásticas convencionais [17]. Um resíduo que apresenta granulometria semelhante ao do resíduo do pó de coletor estudado é a cinza volante, no entanto é possível a incorporação de grandes quantidades desse resíduo em formulações cerâmicas para produção de blocos e telhas em virtude de sua elevada reatividade e poder fundente $[26,27]$ nas temperaturas utilizadas para a produção de cerâmica estrutural. Com a queima ele funde ou reage com a massa argilosa e assim, possíveis efeitos de diminuição do empacotamento podem ser "compensadas" durante a queima.

Outro ponto muito importante a destacar é a granulometria da massa a ser incorporado o resíduo. Massas já utilizadas pelas indústrias cerâmicas, em geral,já apresentam elevada compacidade (obtida experimentalmente ou com a prática de produção), assim a inserção de qualquer tipo de resíduo, com elevada finura ou não, pode comprometer o empacotamento do sistema, apesar de na grande maioria dos trabalhos envolvendo a reciclagem de resíduo serem utilizadas massas industriais. Assim, com base nos dados obtidos, evidencia-se que quando da necessidade de incorporar resíduos em formulações cerâmicas é interessante se utilizar mais de um tipo de argila de modo a poder, quando da combinação com os resíduos, se obter massas com distribuição granulométrica que permitam alta compacidade no produto conformado.

\section{CONCLUSÃO}

Esse trabalho teve por objetivo a caracterização do resíduo do pó de coletor da produção de alumina eletrofundida e a avaliação de sua aplicabilidade como matéria-prima cerâmica alternativa para a produção de blocos e telhas cerâmicos. $\mathrm{O}$ resíduo apresenta uma elevada finura, com tamanho médio de partículas de $9,5 \mu \mathrm{m}$ e $100 \%$ do material com granulometria inferior a $50 \mu \mathrm{m}$. O resíduo é constituído basicamente por alumina e pequenos teores de metais e óxidos fundentes. A absorção de água e o módulo de ruptura diminuem com a elevação do teor de resíduo incorporado a massa, independentemente da temperatura de queima; que é possível incorporar até $20 \%$ de resíduo do pó de coletor em formulação para produção de tijolos furados e telhas quando da queima a $1000{ }^{\circ} \mathrm{C}$ dos corpos, por esses apresentarem valores de absorção de água e módulo de ruptura dentro dos limites preconizados na literatura para cerâmica vermelha.

\section{AGRADECIMENTOS}

Ao CNPq (Proc. 475010/2007-8) pelo apoio financeiro. 


\section{REFERÊNCIAS}

[1] A. M. Bernardin, D. S. Felisberto, M. T. Daros, H. G. Riella, Cerâm. Ind. 11, 5-6 (2006) 31.

[2] R. R. Menezes, G. A. Neves, H. C. Ferreira, Environmental Management and Health 13 (2002) 134.

[3] R. R. Menezes, R. R. Almeida, L. N. L. Santana, H. S. Ferreira, G. A. Neves, H. C. Ferreira, Revista Matéria 12, 1 (2007) 226.

[4] R. R. Menezes, G. A. Neves, H. C. Ferreira, Rev. Bras. Eng. Agr. Amb. 6, 2 (2002) 303.

[5] I. Tiruta-Barna, E. Benetto, Y. Perrodin, Resources, Conservation and Recycling 50 (2007) 351.

[6] F. Andreola, L. Barbieri, A. Corradi, I. Lancellotti, T. Manfredini, J. Eur. Ceram. Soc. 22 (2002) 1457.

[7] P. Torres, H. R. Fernandes, S. Agathopoulos, D. U. Tulyaganov, J. M. F. Ferreira, J. Eur. Ceram. Soc. 24 (2004) 3177.

[8] R. R. Menezes, H. S. Ferreira, G. A. Neves, H. L. Lira, H. C. Ferreira, J. Eur. Ceram. Soc. 25 (2005) 1149.

[9] F. Raupp-Pereira, M. J. Ribeiro, A. M. Segadães, J. A. Labrincha, J. Eur. Ceram. Soc. 27 (2007) 2333.

[10] G. E. Oliveira, J. N. F. Holanda, J. N. F., Waste Management, Res. 22 (2004) 358.

[11] C. M. F. Vieira, T. M. Soares, R. Sánchez, S. N. Monteiro, Mater. Sci. Eng. A 373 (2004) 115.

[12] K. Dana, J. Dey, S. K. Das, Ceram. Int. 31 (2005) 147. [13] S. R. Bragança, J. Vicenzi, K. Guerino, C. P. Bergmann, Waste Management Res. 24 (2006) 60.

[14] R. R. Menezes, H. G. Malzac Neto, L. N. L. Santana,
H. L. Lira, H. S. Ferreira, G. A. Neves, J. Eur. Ceram. Soc. 28 (2008) 3027.

[15] R. R. Almeida, Reciclagem de resíduo de caulim e granito para produção de blocos e telhas, Diss. Mestrado, Universidade Federal de Campina Grande, Campina Grande, PB (2006).

[16] ABNT, Solo - Análise granulométrica - Método de Ensaio, NBR 7181, Rio de Janeiro, RJ (1984).

[17] S. F. Pracidelli, F. G. Melchiades, Cerâm. Ind. 2 (1997) 31.

[18] G. P. Souza, R. Sanchez, J. N. F. Holanda, Cerâmica 48 (2002) 102.

[19] C. M. F. Vieira, T. M. Soares, S. N. Monteiro, Cerâmica 49 (2003) 245.

[20] R. S. Macedo, R. R. Menezes, G. A. Neves, H. C. Ferreira, Cerâmica 54 (2008) 411.

[21] L Barzagui, A. Salge, Cerâmica 28 (1982) 15.

[22] P. Souza Santos. Ciência e Tecnologia de Argilas. $3^{\mathrm{a}}$ Ed., vol. 1, Edgard Blücher, S. Paulo, SP (1992) p. 408.

[23] M. C. Zanetti, S. Fiori, Waste Management Res. 21 (2003) 235.

[24] G. P. Souza, J. N. F. Holanda, Ceram. Int. 30 (2004) 99.

[25] Y. Pontikes, L. Esposito, A. Tucci, G. N. Angelopoulos, J. Eur. Ceram. Soc. 27 (2007) 1657.

[26] A. Olgun, Y. Erdogan, Y. Ayhan, B. Zeybek, Ceram. Int. 31 (2005) 153.

[27] C. A. García-Ubaque, J. C. Moreno-Piraján, L. GiraldoGutierrez, K. Sapag, Waste Management Res. 25 (2007) 352.

(Rec. 14/09/2009, Rev. 21/01/2010, Ac. 22/01/2010) 